23 McElroy SL, Frye MA, Hellemann G, Altshuler L, Leverich GS, Suppes T, et al. Prevalence and correlates of eating disorders in 875 patients with bipolar disorder. J Affect Disord 2011; 128: 191-8.

24 Hudson Jl, Hiripi E, Pope Jr HG, Kessler RC. The prevalence and correlates of eating disorders in the national comorbidity survey replication. Biol Psychiatry 2007; 61: 348-58.

25 Riglin L, Collishaw S, Richards A, Thapar AK, Maughan B, O'Donovan MC, et al Schizophrenia risk alleles and neurodevelopmental outcomes in childhood: a population-based cohort study. Lancet Psychiatry 2017; 4(1): 57-62.

26 Christensen SS, Bentz M, Clemmensen L, Strandberg-Larsen K, Olsen EM. Disordered eating behaviours and autistic traits-Are there any associations in nonclinical populations? A systematic review. Eur Eat Disord Rev 2019; 27: 8-23.

27 Raffi AR, Rondini M, Grandi S, Fava GA. Life events and prodromal symptoms in bulimia nervosa. Psychol Med 2000; 30: 727-31.

28 Westwood H, Eisler I, Mandy W, Leppanen J, Treasure J, Tchanturia K. Using the autism-spectrum quotient to measure autistic traits in anorexia nervosa: a systematic review and meta-analysis. J Autism Dev Disord 2016; 46: 964-77.

29 Kothari R, Barona M, Treasure J, Micali N. Social cognition in children at familial high-risk of developing an eating disorder. Front Behav Neurosci 2015; 9: 1-17.

30 Goldschmidt AB, Lavender JM, Hipwell AE, Stepp SD, Keenan K. Emotion regulation and loss of control eating in community-based adolescents. J Abnorm Child Psychol 2017; 45: 183-91.
31 Macht M, Simons G. Emotions and eating in everyday life. Appetite 2000; 35: 65-71.

32 Perry Bl, Upthegrove R, Thompson A, Marwaha S, Zammit S, Singh SP, et al. Dysglycaemia, inflammation and psychosis: findings from the UK ALSPAC birth cohort. Schizophr Bull 2018, in press

33 Chadda R, Ramshankar P, Deb K, Sood M. Metabolic syndrome in schizophrenia: differences between antipsychotic-naïve and treated patients. J Pharmacol Pharmacother 2013; 4: 176.

34 Succurro E, Segura-Garcia C, Ruffo M, Caroleo M, Rania M, Aloi M, et al. Obese patients with a binge eating disorder have an unfavorable metabolic and inflammatory profile. Medicine (Baltimore) 2015; 94: e2098.

35 So H-C, Chau K-L, Ao F-K, Mo C-H, Sham P-C. Exploring shared genetic bases and causal relationships of schizophrenia and bipolar disorder with $28 \mathrm{car}$ diovascular and metabolic traits. Psychol Med 2018, in press.

36 Manu P, Dima L, Shulman M, Vancampfort D, De Hert M, Correll CU. Weight gain and obesity in schizophrenia: epidemiology, pathobiology, and management. Acta Psychiatr Scand 2015; 132: 97-108.

\section{psychiatry in philosophy}

\section{The language game of psychiatry}

\section{Gunjan Sharma}

'The arrow points only in the application that a living being makes of it.'

- Wittgenstein

Language is a fascinating concept, especially when viewed through the lens of psychiatry. The psychiatrist must rely on words, tone and behaviour to make an assessment of the patient in front of them. This is what Wittgenstein called the 'language game'.

Wittgenstein was a philosopher best known for his work Philosophical Investigations. In it, he argues that the meaning of a word is in the way it is used; i.e., the context, culture and society in which it is used. Thus, the word 'depression' can have a different meaning for a junior doctor studying for their MRCPsych exam, a teenager living in Manchester and a middleaged South Asian woman starting a new life in Bristol. Wittgenstein called this context the 'form of life'.

Wittgenstein compares the use of language with tools in a toolbox. The correct tool must be chosen depending on the context; a screwdriver is of no use if one wishes to hammer a nail. Likewise, what do the words 'anhedonia' or 'low selfesteem' mean to a young woman if her form of life is her role as a mother, her financial difficulties or her experiences as a child? The meaning of these words may be vastly different for the psychiatrist and the patient; they are both playing a different language game.

For Wittgenstein, language is indeed just a game; it does not reflect the truths of the universe or the logic of our minds. For example, I can use the language game to elicit through our shared culture signs and symptoms of major depressive disorder from my patient's monotone voice or use of words enriched with melancholy, but this does not tell me what they are truly feeling. I can sympathise but I cannot empathise. I can only make assumptions based on the game that we play.

As clinicians, we try to adapt our language game in an attempt to objectify patient experience by using tools such as rating scales and the Mental State Examination. But we must remember that such instruments merely reflect our own language game. They may be helpful when used within the clinical context if our aim is to make a clinical diagnosis, but may become inappropriate if used in the language game with a patient for whom such tools take on a different, perhaps negative, meaning.

Philosophical Investigations encourages us to think about the words that we use and the responses they elicit. It highlights the barriers that words can create and the difficulties patients face when they attempt to mould their personal experience into the language game. Wittgenstein's work offers an enlightening read for those interested in language, and is just as relevant to psychiatry as it is to philosophy today. 